\title{
Evaluation of antiparasitic therapy directly administered for the control of canine echinococcosis in an endemic area of hydatidosis.
}

\section{Raul Montalvo ( $\sim$ otivo3@hotmail.com )}

Facultad de medicina Humana, Universidad Nacional del Centro del Perú, Huancayo, Perú https://orcid.org/0000-0003-0227-8850

\section{Alaina Huiza}

Universidad Nacional Mayor de San Marcos

Johana Clemente

Universidad Continental

Lorena Castañeda

Universidad Continental

\section{Yoli Ccente}

Universidad Continental

\section{Mayori Nuñez}

Universidad Continental

\section{Lizet Arteaga}

Universidad Continental

\section{Lizzeth Balbuena}

Universidad Continental

\section{Cristhian Inga}

Universidad Continental

\section{Research article}

Keywords: cystic echinococcosis, hydatidosis, Echinococcus granulosus, zoonoses, parasitic diseases, Control programme, Praziquantel

Posted Date: August 11th, 2020

DOI: https://doi.org/10.21203/rs.3.rs-24656/v2

License: (c) (1) This work is licensed under a Creative Commons Attribution 4.0 International License.

Read Full License 


\section{Abstract}

Background: Echinococcosis remains endemic despite attempts to reduce the prevalence of this disease. The dog faeces were analyzed by coproantigen using the immunoenzymatic technique for the diagnosis of echinococcosis before and after the direct and observed administration of praziquantel $5 \mathrm{mg}$ by $\mathrm{kg}$ orally in three doses every 30 days each cycle was 2 times at year for two consecutive years. The objective of the study was to evaluate the results of an intervention program based on antiparasitic therapy directly administered to the dogs for the control of Echinococcus in an endemic area of cystic echinococcosis (CE).

Results: A total of 252 dogs entered the study, of them 119 (47\%) dogs had positive results for Echinococcus at the beginning of the intervention. The adverse effects that occurred with the administration of prazicuantel were vomiting (13\%), diarrhea (2.4\%) and lethargy (2\%); 229 dogs completed the 4 cycles of praziquantel treatment. The presence of a positive coproantigen was evident in $03(1.3 \%)$ dogs at the end of the study.

Conclusions: Antiparasitic chemotherapy administered directly to the dogs periodically managed to reduce the prevalence of canine echinococcosis.

\section{Background}

Echinococcus granulosus is the parasitic agent that causes $C E$, it is found in the small intestine of its definitive host, dog, which can eliminate up to a quarter of a million eggs during all his life[1-2], When cattle feed on these contaminated meadows, they have high probability of becoming infected, the eggs enters orally and becomes they break in the stomach releasing the oncosphere which migrates to the mainly viscera tissues where they develop cystically and the dog is infected again when ingested raw viscera of infected sheep, the human accidentally becomes infected by ingesting the eggs released by parasitized dogs [3-5]. Echinococcosis is common among people living in poor sanitary conditions in developing countries.

In Peru, the practice of sacrificing adult sheep for domestic consumption and allowing dogs to feed on infected viscera generates the ideal conditions for the persistence of this disease [6-7]. In some rural areas the prevalence of infection can reach up to $50 \%$ [8].

Some programs that attempted to control canine echinococcosis with the massive administration of praziquantel have been able to reduce the prevalence of CE from 22.1 per 100,000 to 6.2 per 100,000, with persistence of high transmission rates in some focal areas [9-10], while others studies have obtained little encouraging results, because it has not been possible to raise awareness about the need for canine prophylaxis and the lack of permanent control programs [11-14]

The objective of the study was to evaluate the results of an intervention program based on antiparasitic therapy directly administered for the control of canine Echinococcosis in an endemic area of CE. 


\section{Results}

A total 252 were analyzed before administering the antiparasitic, 119 (47\%) dogs presented positive results to Echinococcus in the stool sample by coproantigen study, while $133(53 \%)$ dogs showed negative results for the coproantigen study. The other parasitic found with the microscopic examination of the feces, at the beginning of the study, were Toxocara canis, Balantidium coli, Entamoeba coli, Blastocystis hominis, Endolimax nana, Entamoeba coli, giardia canis, Taenia spp eggs, Fasciola hepática, Urbanorum spp, Dipylidium caninum, Ancylostoma; 9 out of 10 dogs had at least one parasite.

The average age of the dogs was 33 months, the male sex was the most frequent representing $72 \%$ of the dogs; the number of dogs chosen was related to the proportion of inhabitants in each community; overall, the average number of dogs per home was 2.4; this being higher average in the houses of infected dogs (2.5) compared to non-infected dogs whose average number of dogs per house was $2.2(p=0.0025)$.

The dogs coming from the street or homeless were 21 (8.3\%), of which $17(80.9 \%)$ dogs presented positive results to the coproantigen study $(p=0.001)$, the owned dogs were $231(91.7 \%)$, of them 102 (44.2\%) presented positive results to the study of the coproantigen for Echinococcus granulosus (Table 1).

Overall, 73 dogs (29\%) had ever received antiparasitic treatment in the last year, of which 27 (36.9\%) dogs had a positive result for infection with Echinococcosis; It is characteristic in these rural areas that dogs share their home with sheep raising, it was found that 79 (31\%) dogs live together with sheep.

The treatment administered was independent of the result of the coproantigen test obtained, all dogs received 02 cycles of antiparasitic treatment with praziquantel per year for two consecutive years, each cycle was composed of 03 doses with a difference of 30 days between each dose. There were reported complications : 13 (5.2\%) dogs had vomiting after receiving the antiparasitic, 6 (2.4\%) dogs had diarrhea, $5(2 \%)$ had drowsiness or lethargy, however, the most severe complication was the death of $02(0.8 \%)$ dogs after 7 days of the first dose, these dogs came from the same house, it is very difficult to associate this death of dogs with the Praziquantel.

During the follow-up, some dogs left the study because they died ( 2 dogs), the owners moved to another community (4 dogs), the owners refused to continue the study (3 dogs), the owner or dog was not found by more than two months ( 6 dogs) and some street dogs ceased to be seen ( 8 dogs).

After two years, 229 dogs completed the 4 cycles of the administration of praziquantel, subsequently they were evaluated by studying stool samples to verify the presence of Echinococcus infection, the procedure was performed in the same way as before program intervention. Of the 229 samples analyzed, 03 (1.3\%) dogs presented positive coproantigene after direct antiparasitic intervention, these 03 infected dogs were street dogs, 02 came from Usibamba and one from Chaquicocha (Table 2).

Table 1. General characteristics of the dogs at the beginning of the intervention. 


\begin{tabular}{|c|c|c|c|c|}
\hline Characteristics & $\begin{array}{c}\text { Total } \\
\mathrm{n}=252\end{array}$ & Echinococcuspositive = 119 (47\%) & Echinococcus negative $=133(53 \%)$ & $\mathrm{p}^{\&}$ \\
\hline Edad promedio* & 33.4 & 33.8 & 33.1 & 0.87 \\
\hline Sex: & & & & 0.88 \\
\hline Male & $183(72.6 \%)$ & $86(46.9 \%)$ & $97(53.1 \%)$ & \\
\hline Female & $69(27.4 \%)$ & $33(53.1 \%)$ & $36(46.9 \%)$ & \\
\hline Prevalence & & & & 0.011 \\
\hline Usibamba & $141(55.9 \%)$ & 77(54.6\%) & $64(45.4 \%)$ & \\
\hline Chaquicocha & $111(44.1 \%)$ & $42(37.8 \%)$ & $69(62.2 \%)$ & \\
\hline Average dogs per house & 2.4 & 2.5 & 2.2 & 0.025 \\
\hline Life style & & & & 0.001 \\
\hline Stray dog & $21(8.3 \%)$ & $17(80.9 \%)$ & $4(19.1 \%)$ & \\
\hline Owned dogs & $231(91.7 \%)$ & $102(44.2 \%)$ & $129(55.8 \%)$ & \\
\hline Previous antiparasitic treatments & & & & 0.09 \\
\hline Yes & $73(28.9 \%)$ & $27(36.9 \%)$ & $46(63.1 \%)$ & \\
\hline Not & 179(71.1\%) & $92(51.4 \%)$ & $87(48.6 \%)$ & \\
\hline Dog live together with sheeps. & $79(31.34 \%)$ & $42(53.2 \%)$ & $37(46.8 \%)$ & 0.011 \\
\hline
\end{tabular}

* Age in months. \& Fisher's exact test was used to calculate the p-value in the case of categorical variables, and Student $t$ test for numerical variables.

Table 2. Prevalence of dogs infected with Echinococcus granulosus: comparison before and after the intervention.

\begin{tabular}{lll}
\hline & Infected dogs before the intervention $=119$ & Infected dogs After the intervention = 3 \\
\hline $\begin{array}{l}\text { Echinococcus positive } \\
\text { Prevalence }\end{array}$ & $119(47.2 \%)$ & $3(1.2 \%)$ \\
Usibamba & $77(54.6 \%)$ & $2(66.6 \%)$ \\
Chaquicocha & $42(37.8 \%)$ & $1(33.4 \%)$ \\
Stray dog & $17(14.3 \%)$ & $3(100 \%)$ \\
\hline
\end{tabular}

\section{Discussion}

Direct administration ensured the correct dose and frequency or administer a second dose in case of vomiting to ensure compliance with antiparasitic treatment, because our objective was to evaluate the results of an intervention program based on antiparasitic therapy directly administered for control of canine Echinococcosis. The initial prevalence of $47 \%$ was evidenced and after the intervention, two years later, the prevalence was reduced to $1.3 \%$ in the two rural communities. Increasing continuous cycles of canine deworming with praziquantel ensures a decrease in the prevalence of Echinococcus reinfection after two years of intervention.

CE is still considered as an unattended zoonotic disease with great economic impact in rural areas (17) and in communities with cold weather that favors the viability of Echinococcus eggs in the environment for several months [18-19]. 
In some countries it is considered a reemerging disease, because it is very difficult to control or eliminate, mainly in more remote areas and difficult to access. Massive treatment with praziquantel has proven effective in some countries and in others not so much due to the different schemes they use, noncompliance with doses, non-supervision of medication administration, non-permanent and non-periodic programs. Many of these programs are costly in financial terms, but beneficial in terms of disease expenses, but poorly assessed in relation to impact [20-22].

Praziquantel is effective in the treatment of echinococcosis, reduces the burden of infection in dogs and indirectly in sheep, but does not protect against future reinfections if the treatment is not continuous and cyclic, so it can explain the poor decrease in prevalence in places where short deworming and the schemes are prophylactic and discontinuous.

The use of praziquantel as preventive chemotherapy, that is to say to administer periodic treatment in populations at risk, is approved by the World Health Organization to reduce the disease burden of some pathology such as schistosomiasis, whose objective is to prevent infected hosts from developing the chronic disease and cure mild symptoms [23-25]. Although reinfection can occur after treatment, it is still considered the main effective measure in the fight against echinococcosis.

Praziquantel is the treatment of choice against Echinococcus, it seems to be a safe medication with good tolerance levels, safety, easy to administer but with little effect on young stages of parasites, with some adverse effects evidenced in the study as vomiting, diarrhea and lethargy that were self-limited [26-27]; However, the efficacy of praziquantel depends on the host's immune response, and the severity of side effects may increase in hyperinfested dogs after administration of the antiparasitic causing a severe inflammatory response [28], this may explain the death of two dogs that They received praziquantel at the first dose.

Attempts to eliminate canine echinococcosis take years because effective control has not been achieved, however in some countries they have been reduced to undetectable levels thanks to the sustained effort of programs based on continuous deworming.

Some limitations found in the study is that the positive coproantigen test may be higher than reported because this test does not usually detect low parasite loads in the stool [29], however to compare the response to the antiparasitic was used the same test before and after administration of praziquantel.

The advantages of this intervention study is that infection surveillance in dogs is non-invasive through the stool samples collected from the ground (30). This control program was only applied in two communities and we do not have data to evaluate the gradual response in time after the two years of intervention, because the study ended, the application of the program being necessary on longer and more sustained time scales to evaluate response and reinfection rates.

\section{Conclusions}


Antiparasitic chemotherapy administered directly to the dogs periodically and sustainably managed to reduce the prevalence of canine echinococcosis and is considered the main effective measure.

\section{Methods}

\section{Population}

Two communities were visited in the period May 2015 to December 2017: Usibamba and Chaquicocha, belonging to the San José de Quero district, province of Concepción, located in central Peru at 4000 meters above sea level with temperatures ranging from $-4^{\circ} \mathrm{C}$ to $16^{\circ} \mathrm{C}$. These two communities have 2193 inhabitants and are endemic of CE (Graph 1).

There are not sufficient information about the number of dogs that living in the study area to evaluate the sample size, it was calculated on an unknown population with an expected prevalence of $28 \%$ of dogs infested with $E$. granulosus in endemic areas [15], $95 \%$ as a confidence interval, power of $80 \%$ and adding $10 \%$ for probable losses. The sample tested was 260 stool samples, using the proportions method with the statistical program Stata v. 13.1 (Stata Corporation, Texas, USA).

\section{Procedures:}

An epidemiological study of canine echinococcosis was performed. Before the intervention, the houses were chosen at random according to the proportion of inhabitants of each community and each street, with the support of the demographic survey of the municipality of San José de Quero,, on satellite images and on the map geographical All the dogs present in each house were sampled, if the occupants of a house were absent, refused to participate in the study or had no dog, we selected a neighboring house and asked about the presence or absence of dogs. The process was continued until the sample size was completed.

Prior informed consent to the owners, the information was collected by means of a structured and validated form, as well as the measures of prevention of $\mathrm{CE}$, a leaflet containing information on the importance of deworming was given and obtained samples of Fresh feces, maintaining the biosecurity measures, the samples were deposited in a bottle with $10 \%$ formalin and kept refrigerated at $4{ }^{\circ} \mathrm{C}$, then transported to the microbiology laboratory of the Institute of Tropical Medicine - University National Mayor of San Marcos for microscopic identification. Samples of fresh feces were also collected from the fields and from the main square of the annexes in order to compare the results microbiologically.

For the microscopic examination of faecal samples preserved in $10 \%$ formalin, select the direct method that consists of dissolving the sample well, keeping it at rest for 5 minutes and with the help of a Pasteur pipette, take a drop from the bottom and place it in a slide, protected with a coverslip and observe under a microscope at a magnification of 10 and 40 . The objective of this procedure was to identify the presence of other parasites. 
For the diagnosis of echinococcosis, analyze stool samples from the dogs by using coproantigen analysis, using the commercial immunoenzymatic technique (ELISA) for E. granulosus (Cestodas Zoonoses Research Group, University of Salford). The plates were read at $490 \mathrm{~nm}+-3$ standard deviations with a kinetic microplate reader. Two positive and two negative controls are used per plate [16]. The same stool sample was used for both techniques.

Intervention

Due to the unevenness of the work area surface, an electronic foot scale was used to calculate the dog's weight, the owner loaded the dog to the scale, then subtracted the difference from the owner's weight to obtain the dog's weight. For stray dogs, the weight of the dogs was calculated approximately according to external characteristics.

The dogs received 4 cycles of treatment, with an interval of 6 months between each cycle, in each cycle they received three doses of praziquantel, one per month. The first cycle of treatment started in July 2014, the second cycle started in April 2015, the third cycle started in January 2017, and the last cycle started in October 2017. Dog feces samples were collected at the beginning of the first cycle and at the end of the fourth cycle of treatment.

Praziquantel $5 \mathrm{mg} / \mathrm{kg}$ was administered orally to dogs every 30 days for three consecutive months, every 6 months for two years, the dogs received 12 doses in 2 years. The Stray dogs found in parks were also dewormed, praziquantel was combined with bread or chicken, stray dogs received a dose and frequency similar to other dogs, a photograph was selected in each deworming process to identify the dog. The administration of the medication went directly to the dog and under supervision, the medication was not delivered to the owner or to the health facility.

At each home visit, messages on EC prevention and the delivery of informational materials were reinforced, an antiparasitic card was also given to the owner and marked every time the dog received antiparasitic treatment, in the same way that it was obtained Information on the adverse effects presented by the dog When the owner was not found, we visited him the next day until we were able to deworm the dogs.

After two years, in December 2017, we collected the stool samples again in the same way as before the intervention and transported them to the microbiology laboratory to identify the parasite.

Statistical analysis

Microsoft Excel for Windows was utilized for double data entry process. STATA version 12.0 for Windows (STATA Corp, College Station, TX, US) was used for analysis. Initially, a description of demographic characteristics was tabulated according to general characteristics of the dogs before the intervention. Categorical variables were compared using Chi squared or Fisher's exact test as appropriate, whereas numerical variables were compared using the Student's t test. In addition, mean of quantitative variables 
such as dog age and number of dogs per house, were calculated for each group according to the positive or negative Echinococcus result.

\section{Abbreviations}

Kg: kilogram; ${ }^{\circ}$ C: centigrade degree; E. granulosus: Echinococcus granulosus, \%: percentage; WHO: World Health Organization

\section{Declarations}

\section{Ethics approval and consent to participate}

The study protocol was approved by The Local Ethic Medical Committee (CEI No. 21-2015/OCDI-HRDCQDAC). Written informed consents were obtained from the participants and and owners of the dogs.

\section{Consent for publication}

Not applicable.

\section{Availability of data and materials}

The dataset supporting the findings of this article is available from the corresponding author upon request.

\section{Competing interests}

The authors declare that they have no competing interests.

\section{Funding}

This project has been supported by the National University of Central Peru for the laboratory tests and the Continental University for the administration of medications, through the Research Institute.

\section{Authors' contributions}

RM performed the study design and data analyses. JC, LC performed experimental assays and data analysis. LC, YC, MN, LA performed data collection and analysis; AH performed in tests; LB performed clinical diagnostics; $\mathrm{Cl}$, LA performed data collection and manuscript preparation; RM, AH performed study design, data analysis and manuscript preparation. All authors read and approved the final manuscript.

\section{Acknowledgements}

We are grateful for the collaboration of the serum doctors of the health centers of the communities Dra Sofía Olivera Núñez and Dr. Juan José Flores 


\section{Author details}

${ }^{1}$ Faculty of Human Medicine, Universidad Nacional del Centro del Perú, Huancayo, Perú. ${ }^{2}$ Institute of Tropical Medicine, National University of San Marcos, Peru. ${ }^{3}$ Continental University School of Medicine, Perú.

\section{References}

1. Craig PS, Giraudoux P, Wang ZH, Wang Q. Echinococcosis transmission on the Tibetan Plateau. Adv Parasitol. 2019;104:165-246. doi:10.1016/bs.apar.2019.03.001

2. Boufana B, Lett W, Lahmar S, et al. Canine echinococcosis: genetic diversity of Echinococcus granulosus sensu stricto (s.s.) from definitive hosts. J Helminthol. 2015;89(6):689-698. doi:10.1017/S0022149X15000395

3. Merino V, Westgard CM, Bayer AM, García PJ. Knowledge, attitudes, and practices regarding cystic echinococcosis and sheep herding in Peru: a mixed-methods approach. BMC Vet Res. 2017;13(1):213. Published 2017 Jul 6. doi:10.1186/s12917-017-1130-4

4. Quispe Pari JF, Loyola Almonacid F, Mallma Gomez E, et al. Subcutaneous hydatidic cyst: report of two cases in Huancayo, Peru. Rev Peru Med Exp Salud Publica. 2018;35(4):684-688. doi:10.17843/rpmesp.2018.354.3767

5. Pavletic CF, Larrieu E, Guarnera EA, et al. Cystic echinococcosis in South America: a call for action. Rev Panam Salud Publica. 2017;41:e42. Published 2017 Aug 21. doi:10.26633/RPSP.2017.42

6. Larrieu E, Gavidia CM, Lightowlers MW. Control of cystic echinococcosis: Background and prospects. Zoonoses Public Health. 2019;66(8):889-899. doi:10.1111/zph.12649

7. Merino V, Westgard CM, Bayer AM, García PJ. Knowledge, attitudes, and practices regarding cystic echinococcosis and sheep herding in Peru: a mixed-methods approach. BMC Vet Res. 2017;13(1):213. Published 2017 Jul 6. doi:10.1186/s12917-017-1130-4

8. Montalvo R, Clemente J, Castañeda L, Caro E, Ccente Y, Nuñez M. Coproprevalence of Canine Infestation by Echinococcus granulosus In An Endemic Hidatidosis District In Peru. RIVEP. 14mar.2018;29(1):263-9. DOI: https://doi.org/10.15381/rivep.v29i1.14189

9. Larrieu E, Zanini F. Critical analysis of cystic echinococcosis control programs and praziquantel use in South America, 1974-2010. Rev Panam Salud Publica. 2012;31(1):81-87. doi:10.1590/s102049892012000100012

10. Larrieu E, Seleiman M, Herrero E, et al. Vigilancia de la equinococosis quística en perros y niños en la provincia de Río Negro, Argentina [Cystic echinococcosis in dogs and children in the province of Río Negro, Argentina]. Rev Argent Microbiol. 2014;46(2):91-97. doi:10.1016/S0325-7541(14)70054-9

11. Van Kesteren F, Qi X, Tao J, et al. Independent evaluation of a canine Echinococcosis Control Programme in Hobukesar County, Xinjiang, China. Acta Trop. 2015;145:1-7. doi:10.1016/j.actatropica.2015.01.009 
12. Farias LN, Malgor R, Cassaravilla C, Bragança C, de la Rue ML. Echinococcosis in southern Brazil: efforts toward implementation of a control program in Santana do Livramento, Rio Grande do Sul. Rev Inst Med Trop Sao Paulo. 2004;46(3):153-156. doi:10.1590/s0036-46652004000300006

13. Andersen FL, Tolley HD, Schantz PM, Chi P, Liu F, Ding Z. Cystic echinococcosis in the Xinjiang/Uygur Autonomous Region, People's Republic of China. II. Comparison of three levels of a local preventive and control program. Trop Med Parasitol. 1991;42(1):1-10.

14. Zhang W, Zhang Z, Wu W, et al. Epidemiology and control of echinococcosis in central Asia, with particular reference to the People's Republic of China. Acta Trop. 2015;141(Pt B):235-243. doi:10.1016/j.actatropica.2014.03.014

15. Acosta-Jamett G, Weitzel T, Boufana B, Adones C, Bahamonde A, Abarca K, Craig P, et al. 2014. Prevalence and risk factors for echinococcal infection in a rural area of northern Chile: a householdbased cross-sectional study. PLoS Negl Trop Dis 8(8): e3090. Disponible en: https://doi.org/10.1371/journal.pntd.0003090

16. Verastegui M, Moro P, Guevara A, Rodriguez T, Miranda E, Gilman RH. 1992. Enzyme-linked immunoelectrotransfer blot test for diagnosis of human hydatid disease. J Clin Microbiol 30: 15571561.

17. Montalvo R, Tiza V. Evaluation of economic expenditure related to human hydatidosis in Junín, Peru. Rev Peru Med Exp Salud Publica. 2017;34(3):445-450. doi:10.17843/rpmesp.2017.343.2521

18. Schurer JM, Rafferty E, Farag M, Zeng W, Jenkins EJ. Echinococcosis: An Economic Evaluation of a Veterinary Public Health Intervention in Rural Canada. PLoS Negl Trop Dis. 2015;9(7):e0003883. Published 2015 Jul 2. doi:10.1371/journal.pntd.0003883

19. Han XM, Cai QG, Wang W, Wang H, Zhang Q, Wang YS. Childhood suffering: hyper endemic echinococcosis in Qinghai-Tibetan primary school students, China. Infect Dis Poverty. 2018;7(1):71. Published 2018 Jul 12. doi:10.1186/s40249-018-0455-y

20. Irabedra P, Ferreira C, Sayes J, et al. Control programme for cystic echinococcosis in Uruguay. Mem Inst Oswaldo Cruz. 2016;111(6):372-377. doi:10.1590/0074-02760160070

21. VAN Kesteren F, Mastin A, Torgerson PR, Mytynova B, Craig PS. Evaluation of the impact of 2 years of a dosing intervention on canine echinococcosis in the Alay Valley, Kyrgyzstan. Parasitology. 2017;144(10):1328-1337. doi:10.1017/S0031182017000397

22. Craig PS, Hegglin D, Lightowlers MW, Torgerson PR, Wang Q. Echinococcosis: Control and Prevention. Adv Parasitol. 2017;96:55-158. doi:10.1016/bs.apar.2016.09.002

23. World Health Organization. Preventive chemotherapy in human helminthiasis. Coordinated use of anthelminthic drugs in control interventions: a manual for health professionals and programme managers. Geneva: WHO; 2006. p. 235-6.

24. Zhang Y, Koukounari A, Kabatereine N, Fleming F, Kazibwe F, Tukahebwa E, et al. Parasitological impact of 2-year preventive chemotherapy on chistosomiasis and soil-transmitted helminthiasis in Uganda. BMC Med. 2007;5:27. 
25. Ouedraogo H, Drabo F, Zongo D, Bagayan M, Bamba I, Pima T, et al. Schistosomiasis in school-age children in Burkina Faso after a decade of preventive chemotherapy. Bull World Health Organ. 2016;94:37-45.

26. Yue WJ, You JQ, Mei JY. Prophylactic activity of praziquantel in animals infected with Schistosoma japonicum. Zhongguo Yao Li Xue Bao. 1985;6: 186-8. (in Chinese)

27. Sabah AA, Fletcher C, Webbe G, Doenhoff MJ. Schistosoma mansoni: chemotherapy of infections of different ages. Exp Parasitol. 1986;61:294-03.

28. Xiao SH, Sun J, Chen MG. Pharmacological and immunological effects of praziquantel against Schistosoma japonicum: a scoping review of experimental studies. Infect Dis Poverty. 2018;7(1):9. Published 2018 Feb 7. doi:10.1186/s40249-018-0391-x

29. Allan JC, Craig PS. Coproantigens in taeniasis and echinococcosis. Parasitol Int. 2006;55 Suppl:S75-S80. doi:10.1016/j.parint.2005.11.010

30. Pierangeli NB, Soriano SV, Roccia I, Bergagna HF, Lazzarini LE, Celescinco A, Kossman AV, Saiz MS, Basualdo JA. Usefulness and validation of a coproantigen test for dog echinococcosis screening in the consolidation phase of hydatid control in Neuquén, Argentina. Parasitol Int. 2010 Sep;59(3):394-9

\section{Figures}




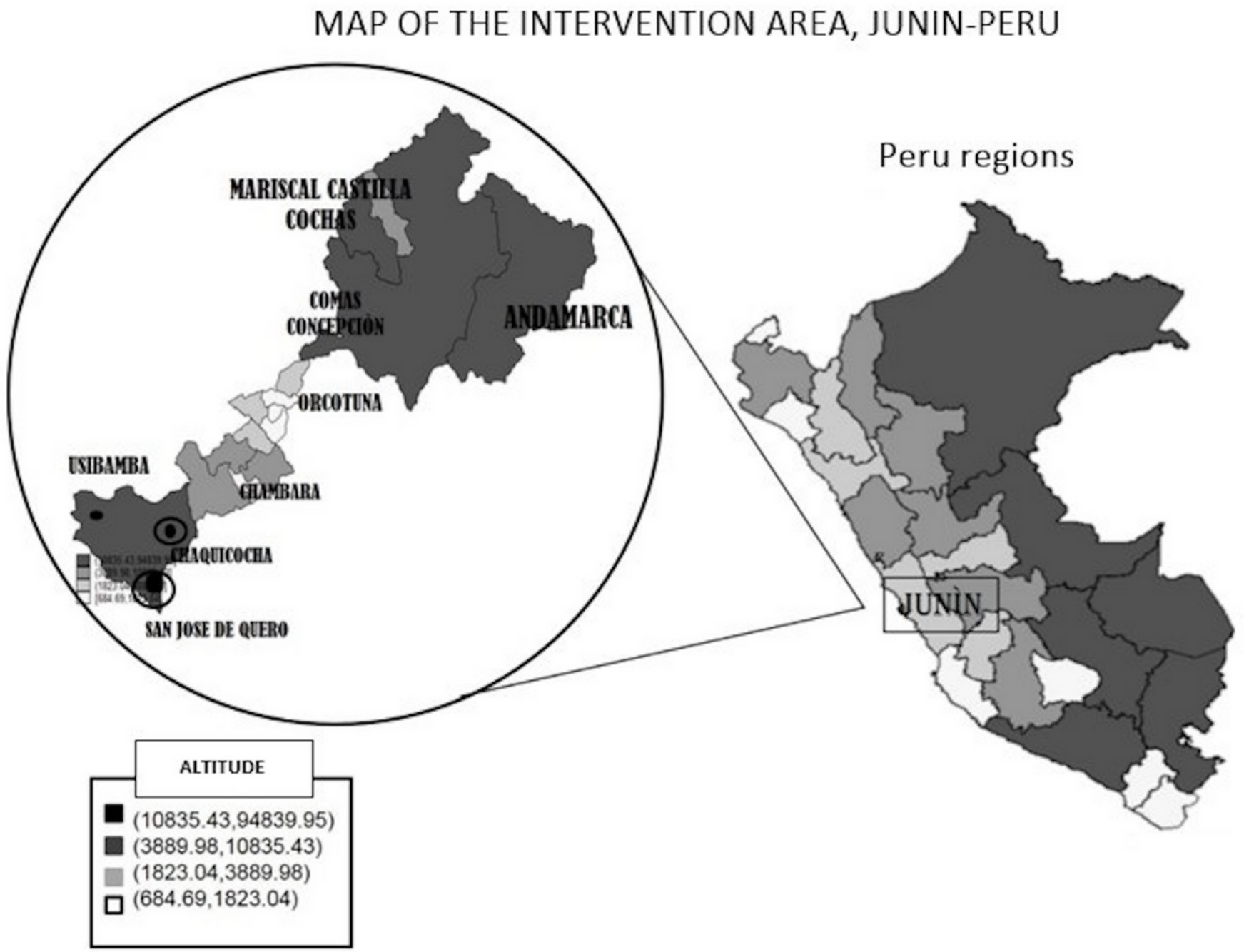

Figure 1

Graph 1. Map of the intervention area for the assessment of therapy directly administered with praziquantel to the dogs, Junín-Perú. Figure created by R. Montalvo, using Stata statistical software version 12.0 for Windows (STATA Corp, College Station, TX, USA) 


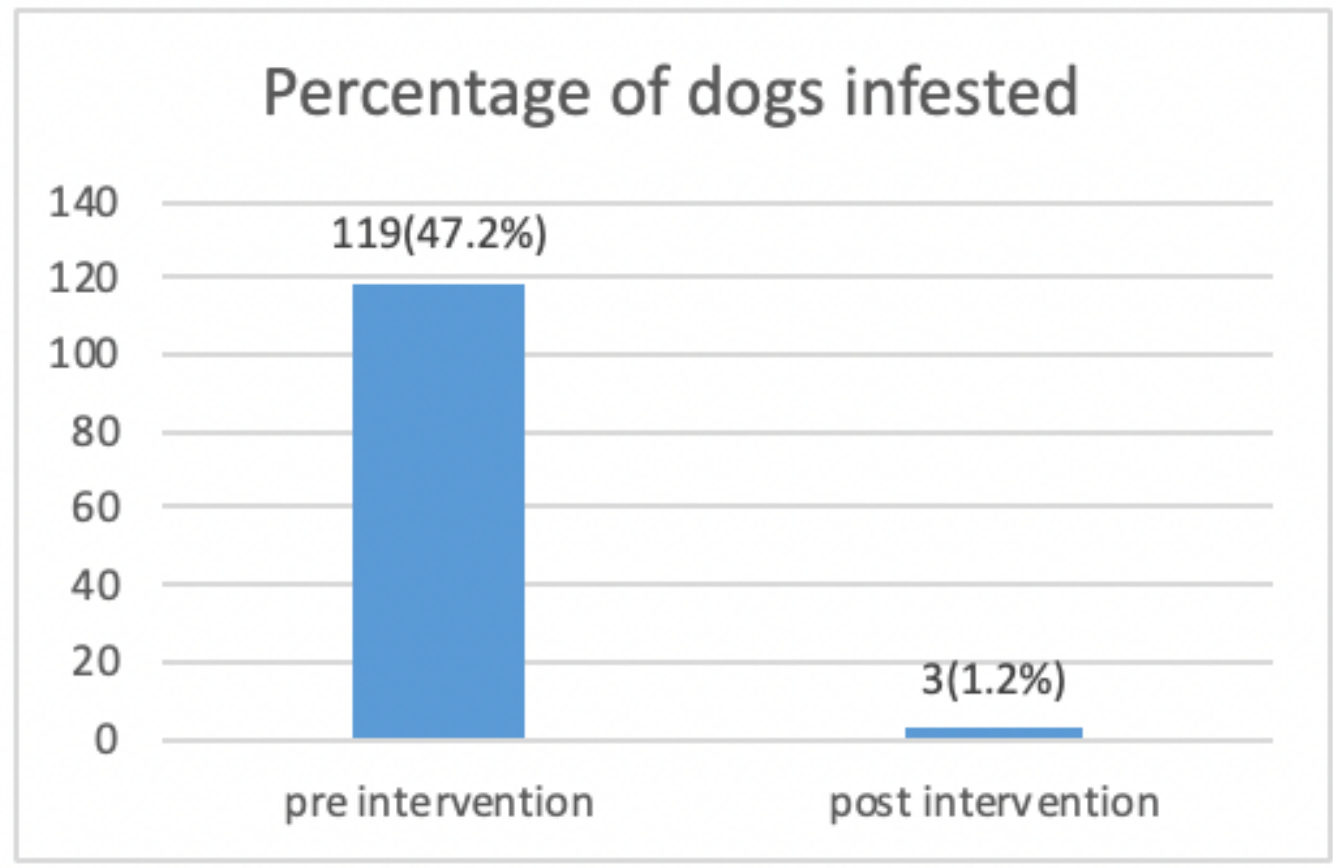

Figure 2

Graph $\mathrm{N}^{\circ} 2$ Percentage of dogs infested by Echinococcus granulosus before and after the intervention, San José de Quero district, Concepción. 